\title{
High incidence of coding gene mutations in mitochondrial DNA in esophageal cancer
}

\author{
ZONG-WEN LIU $^{1 *}$, ZHEN-JIANG GUO $^{1 *}$, A-LAN CHU ${ }^{1}$, YAN ZHANG $^{2}$, BING LIANG $^{3}$, \\ XING GUO $^{1}$, TING CHAI ${ }^{3}$, RUI SONG ${ }^{1}$, GE HOU $^{1}$ and JIN-JIN YUAN ${ }^{1}$

\footnotetext{
${ }^{1}$ Department of Radiotherapy, The Second Affiliated Hospital of Zhengzhou University, Zhengzhou, Henan 450014;

${ }^{2}$ Department of Pharmacology, School of Basic Medicine of Zhengzhou University, Zhengzhou, Henan 450001;
} \\ ${ }^{3}$ Department of Oncology, The Second Affiliated Hospital of Zhengzhou University, Zhengzhou, Henan 450014, P.R. China
}

Received October 14, 2016; Accepted July 6, 2017

DOI: $10.3892 / \mathrm{mmr} .2017 .7663$

\begin{abstract}
The aim of the present study was to detect mutations in the coding genes of mitochondrial DNA (mtDNA) in three esophageal cancer cell lines and in tumor tissues obtained from 30 patients with esophageal cancer, to investigate the relationship between protein- and RNA-coding gene mutations and esophageal cancer. mtDNA was extracted and the coding genes were sequenced and analyzed by comparing the sequencing results with the complete mitochondrial genome of Homo sapiens. The results revealed 39 mutations in the three esophageal cancer cell lines; the genes with the highest mutation frequencies included mitochondrially encoded cytochrome B (MT-CYTB), NADH dehydrogenase 5 (MT-ND5) and MT-ND4 gene. A total of 216 mutations were identified in the 30 esophageal cancer tissues, including 182 protein-coding mutations, of which MT-CYTB and MT-ND5 genes exhibited higher mutation frequencies. The results of the present study indicated that mutations in the coding genes of mtDNA in esophageal cancer cells may be related to the occurrence of esophageal cancer.
\end{abstract}

\section{Introduction}

Tumor development is a multifactorial process involving several steps. It is currently considered that the biological characteristics of a tumor not only depend on the nuclear genetic material, but also have a certain relationship with extranuclear genetic material from mitochondrial DNA (mtDNA) (1). As studies on mitochondria increase in number,

Correspondence to: Dr Yan Zhang, Department of Pharmacology, School of Basic Medicine of Zhengzhou University, 100 Science Avenue, Zhengzhou, Henan 450001, P.R. China

E-mail: docyanzhang@126.com

${ }^{*}$ Contributed equally

Key words: esophageal cancer, mitochondrial DNA, coding gene, mutation it has been revealed that the DNA in the mitochondrial basilar membrane is a unique genetic material that only exists outside the nucleus (2). Mitochondria are cellular organelles that are required for oxidative respiration for the production of energy and are the center of aerobic metabolism; therefore, large amounts of oxygen free radicals are produced during oxidative phosphorylation in the mitochondria, which exposes mtDNA to higher concentrations of reactive oxygen species (ROS) (3). Coinciding with this is an imperfect mtDNA damage repair system and a lack of protection of mtDNA against histone and DNA-binding proteins (4-6). Therefore, mtDNA is more susceptible to attacks by carcinogens, leading to damage and mutation with the mutation rate being 10-20 times higher than that of nDNA (7-10). mtDNA is divided into the non-coding displacement (D)-loop region and the coding region. The majority of previous studies concentrated on the D-loop region of the mtDNA. The D-loop region is of great interest in the area of mtDNA mutations in many tumor tissues, and in non-neoplastic diseases and normal tissues; the D-loop region is also of great interest in the area of mtDNA mutations, indicating that a high rate of mutations in the D-loop region is not specific to tumors. Currently, there are few reports on the relationship between coding gene mutations in mtDNA and tumorigenesis. The present study uses 3 esophageal cancer cell lines and 30 tissue samples from patients with esophageal cancer to investigate the presence of mutations in coding sequences in the mtDNA. The mtDNA genes were sequenced to determine the relationship between the mutations and the occurrence of esophageal cancer.

\section{Materials and methods}

Esophageal carcinoma cell lines. The EC9706 cell line was a gift from The Key Laboratory of State Molecular Oncology, Chinese Academy of Medical Sciences (Beijing, China). The TE-1 and Eca109 cell lines were gifts from The School of Pharmacy, Zhengzhou University (Zhengzhou, Henan, China).

Cell culture. The Ec9706, TE-1 and Eca109 cells were seeded in separate culture flasks with RPMI-1640 medium containing $10 \%$ fetal bovine serum (both Beijing Solarbio Science \& Technology Co., Ltd., Beijing, China), which were then placed 
in an incubator at $37^{\circ} \mathrm{C}$ and $5 \% \mathrm{CO}_{2}$. The culture medium was replaced every two days and cells were grown to $\sim 90 \%$ confluency.

Esophageal cancer tissues. A total of 30 tumor samples were obtained from patients diagnosed with esophageal cancer, who underwent surgery in The First Affiliated Hospital of Zhengzhou University and in The Second Affiliated Hospital of Zhengzhou University (Zhengzhou, China). None of the patients in this study received preoperative treatments, such as chemotherapy or radiotherapy. This study was approved by the Ethics Review Committee of The Second Affiliated Hospital of Zhengzhou University, and all patients provided signed written informed consent. Tumor tissue samples were collected within 30 min following surgical removal and were stored at $-80^{\circ} \mathrm{C}$ until all samples were collected for combined submission for mtDNA sequencing.

Extraction of mtDNA from cells and tissues. For mitochondrial extraction, $\sim 5 \times 10^{7}$ cells from each cell line were required and $\sim 100 \mathrm{mg}$ of each tissue was used. All of the mitochondrial extract was then used to extract mtDNA. Mitochondria were extracted using a Mitochondria Isolation kit (Beijing Solarbio Science \& Technology Co., Ltd.) and the mtDNA was isolated using a Mitochondrial DNA Extraction kit (Shanghai Jiemei Gene Pharmaceutical Technology Co., Ltd., Shanghai, China) according to the manufacturer's protocol. The concentration and purity of mtDNA sample were determined by at least three spectrophotometric measurements, with distilled water used as a blank control. The A260/A280 ratio of pure mtDNA samples was 1.8; a ratio $>1.9$ indicated RNA contamination, and $<1.6$ indicated contamination with proteins, phenol or other agents.

Coding gene sequencing of $m t D N A$ in esophageal cell lines and tissues. The complete mtDNA sequence was $16,569 \mathrm{bp}$ in length. The mtDNA sequence was pieced together from 15 fragments resulting from the polymerase chain reaction (PCR) method; the primer sequences, the length of the 15 sections and their corresponding locations along the mtDNA are provided in Table I. All primers were synthesized by Sangon Biotech Co., Ltd. (Shanghai, China). The $2 \mathrm{X}$ Taq PCR MasterMix (Beijing Biomed Gene Technology Co., Ltd, Beijing, China) containing the Taq DNA polymerase and dNTPs was used. The $25 \mu$ l PCR reaction system contained $1 \mu \mathrm{l}$ of mtDNA, $1 \mu \mathrm{l}$ of forward primer, $1 \mu \mathrm{l}$ of reverse primer, $12.5 \mu \mathrm{l}$ of PCR Master Mix (2X) and $9.5 \mu \mathrm{l}$ of nuclease-free water (Thermo Scientific). The PCR amplification conditions were as follows: Initial denaturation at $95^{\circ} \mathrm{C}$ for $3 \mathrm{~min}$, followed by 35 cycles of denaturation at $94^{\circ} \mathrm{C}$ for $30 \mathrm{sec}$, annealing at $55-60^{\circ} \mathrm{C}$ for $35 \mathrm{sec}$, and extension at $72^{\circ} \mathrm{C}$ for $50 \mathrm{sec}$, and a final extension at $72^{\circ} \mathrm{C}$ for $8 \mathrm{~min}$. A total of $5 \mu 1$ PCR product was mixed with 6X Loading buffer (Beyotime Institute of Biotechnology, Shanghai, China) were checked by electrophoresis on $1 \%$ agarose gel. A 10,000 bp DNA marker was used to determine the size of the amplified fragments; electrophoresis was performed with $0.5 \mathrm{X}$ Tris-borate-EDTA buffer with a constant of $150 \mathrm{~V}$ for $20 \mathrm{~min}$. The gel was visualized with ethidium bromide and imaged by a gel image analyzer. PCR products were excised from the gel and purified using the UNIQ-10 Spin Column DNA Gel Extraction kit (Sangon
Biotech Co., Ltd.) according to the manufacturer's instructions. The purified PCR products were sent to Sangon Biotech Co., Ltd. for sequencing.

mtDNA mutation analysis. To analyze the collected data, ABACUS algorithm based software (Auto-analysis with GeneMapper 4.0) was provided by Sangon Biotech Co., Ltd. Sequence data were analyzed with Sequencing Analysis Software version 5.2 (Applied Biosystems; Thermo Fisher Scientific, Inc., Waltham, MA, USA), Sequence Scanner v1.0 (Applied Biosystems; Thermo Fisher Scientific, Inc.), ChromasPro v2.1.5 (Technelysium Pty., Ltd., South Brisbane, Australia) and EditSeq Lasergene v7.1 (DNASTAR, Inc., Madison, WI, USA). To define the mutation, a revised Cambridge Reference Sequence [rCRS; National Center for Biotechnology Information (NCBI) GenBank accession NC_012920.1; www.ncbi.nlm.nih.gov/nuccore/251831106] was used as the reference sequences.

\section{Results}

mtDNA sequencing analysis of three esophageal cancer cell lines. Following sequencing of the mtDNA coding region in the TE-1, EC9706 and Eca109 cell lines, the sequences were compared with the complete mitochondrial genome of Homo sapiens (NCBI reference sequence NC_012920.1). The sequencing results identified 39 mutations in the 3 cell lines, 38 of which were base substitutions. The majority of the mutations were $\mathrm{A} \rightarrow \mathrm{G}$ or $\mathrm{C} \rightarrow \mathrm{T}$ substitutions; 10 of the identified mutations occurred within all three cell lines, including A750G, A1438G, A2706G, A4769G, C7028T, A8860G, G11719A, C12705T, C14766T and A15326G (Table II). There were three mutations identified that led to an amino acid replacement, including A8860G ( $\mathrm{Thr} \rightarrow$ Ala) in the mitochondrially encoded ATP synthase 6 (MT-ATP6) gene, and C14766T (Thr $\rightarrow$ Ile) and A15326G (Thr $\rightarrow$ Ala) in the cytochrome B (MT-CYTB) gene. A total of 31 protein-coding and 8 RNA-coding mutations were identified (Table III). The mutation frequencies were also assessed by calculating the percentage of the total mutations identified in the 3 cell lines that were also observed in CYTB: Mutation frequency $(\%)=$ number of mutations in CYTB $/ 39$. Among the 31 protein-coding mutations, MT-CYTB, MT-ND5 and MT-ND4 exhibited the highest mutation frequencies of $15.4 \%(6 / 39), 12.8 \%(5 / 39)$ and $12.8 \%(5 / 39)$, respectively.

mtDNA sequencing analysis of 30 esophageal cancer tissues. Similar to the cell lines, the sequences obtained from the 30 tissue samples were compared with the H. sapiens mitochondrial genome NC_012920.1. A total of 216 mutations were identified, including 214 point mutations, one single-nucleotide insertion and one single-nucleotide deletion. A majority of the mutations were $\mathrm{A} \rightarrow \mathrm{G}$ and $\mathrm{C} \rightarrow \mathrm{T}$ substitutions. Among the identified 216 identified mutations, $84.2 \%$ (182/216) occurred in genes involved in mitochondrial respiratory complexes (Table III). MT-ND5, MT-CYTB and MT-ND2 exhibited the highest mutation frequencies at $12.5 \%$ (27/216), 11.1\% (24/216) and $10.2 \%$ (22/216), respectively. In all 30 tissue samples analyzed, the A750G, A4769G, A8860G, G11719A, C14766T and $\mathrm{A} 15326 \mathrm{G}$ mutation sites were observed. In addition, the two mutations, A1438G and A2706G, were identified in 29 
Table I. List of primers used to obtain full-length human mitochondrial DNA sequence.

\begin{tabular}{|c|c|c|c|}
\hline Primer name & Primer sequence $\left(5^{\prime} \rightarrow 3^{\prime}\right)$ & Fragment size (bp) & Starting and ending sites \\
\hline NO1 & $\begin{array}{l}\text { F: AAACAAAGAACCCTAACACCAGC } \\
\text { R: TCATCTTTCCCTTGCGGTACTA }\end{array}$ & 1,443 & $359-1,801$ \\
\hline $\mathrm{NO} 2$ & $\begin{array}{l}\text { F: CCCACTCCACCTTACTACCAG } \\
\text { R: ATAGAAACCGACCTGGATTACT }\end{array}$ & 1,414 & $1,689-3,102$ \\
\hline NO3 & $\begin{array}{l}\text { F: ACCAACGGAACAAGTTACCC } \\
\text { R: TGATAGGTGGCACGGAGAA }\end{array}$ & 1,479 & $2,910-4,388$ \\
\hline NO4 & $\begin{array}{l}\text { F: CCTACCACTCACCCTAGCATTACT } \\
\text { R: TAAAGTGGCTGATTTGCGTTC }\end{array}$ & 1,455 & $4,185-5,639$ \\
\hline NO5 & $\begin{array}{l}\text { F: AAACAATAGCCTCATCATCCC } \\
\text { R: CCGAAGCCTGGTAGGATAAG }\end{array}$ & 1,374 & $5,285-6,658$ \\
\hline NO6 & $\begin{array}{l}\text { F: CAATACCAAACGCCCCTCT } \\
\text { R: TGAGTGTTAGGAAAAGGGCATA }\end{array}$ & 1,290 & $6,435-7,724$ \\
\hline NO7 & $\begin{array}{l}\text { F: GTTTCAAGCCAACCCCATG } \\
\text { R: TTGGTGTAAATGAGTGAGGCAG }\end{array}$ & 1,331 & $7,479-8,809$ \\
\hline NO8 & $\begin{array}{l}\text { F: CCCCACCTCCAAATATCTCA } \\
\text { R: TTGGCGGATGAAGCAGATA }\end{array}$ & 1,254 & $8,619-9,872$ \\
\hline NO9 & $\begin{array}{l}\text { F: CAGGCATCACCCCGCTAA } \\
\text { R: GGTCGGAGGAAAAGGTTGG }\end{array}$ & 1,376 & $9,562-10,937$ \\
\hline NO10 & $\begin{array}{l}\text { F: CACATATGGCCTAGACTACGTACA } \\
\text { R: ATATTTGATCAGGAGAACGTGGT }\end{array}$ & 1,214 & $10,718-11,931$ \\
\hline NO11 & $\begin{array}{l}\text { F: CCACGGGCTTACATCCTCA } \\
\text { R: CCTTCTATGGCTGAGGGGAG }\end{array}$ & 1,340 & $11,713-13,052$ \\
\hline NO12 & $\begin{array}{l}\text { F: ACAGCAGCCATTCAAGCAA } \\
\text { R: GTCAGGGTTGATTCGGGAG }\end{array}$ & 1,450 & $12,832-14,281$ \\
\hline NO13 & $\begin{array}{l}\text { F: TCTTACGAGCCAAAACCTGC } \\
\text { R: GAGGGTGGGACTGTCTACTGAG }\end{array}$ & 1,310 & $13,962-15,271$ \\
\hline NO14 & $\begin{array}{l}\text { F: ACATCGGCATTATCCTCCTG } \\
\text { R: AAGGGATTTGACTGTAATGTGCT }\end{array}$ & 1,271 & $15,087-16,357$ \\
\hline NO15 & $\begin{array}{l}\text { F: ACACCAGTCTTGTAAACCGGA } \\
\text { R: ACTCACTGGAACGGGGATG }\end{array}$ & 1,381 & $15,909-16,569 ; 1-720$ \\
\hline
\end{tabular}

F, forward; NO, number; R, reverse.

Table II. Top 10 common mutations in the three esophageal cancer cell lines.

\begin{tabular}{lccl}
\hline Locus & $\begin{array}{c}\text { Nucleotide } \\
\text { position }\end{array}$ & $\begin{array}{c}\text { Nucleotide } \\
\text { change }\end{array}$ & $\begin{array}{c}\text { Amino } \\
\text { acid change }\end{array}$ \\
\hline MT-RNR1 & 750 & $\mathrm{~A} \rightarrow \mathrm{G}$ & Noncoding \\
MT-RNR1 & 1,438 & $\mathrm{~A} \rightarrow \mathrm{G}$ & Noncoding \\
MT-RNR2 & 2,706 & $\mathrm{~A} \rightarrow \mathrm{G}$ & Noncoding \\
MT-ND2 & 4,769 & $\mathrm{~A} \rightarrow \mathrm{G}$ & Met $\rightarrow$ Met \\
MT-COX1 & 7,028 & $\mathrm{C} \rightarrow \mathrm{T}$ & Ala $\rightarrow$ Ala \\
MT-ATP6 & 8,860 & $\mathrm{~A} \rightarrow \mathrm{G}$ & $\mathrm{Thr} \rightarrow$ Ala \\
MT-ND4 & 11,719 & $\mathrm{G} \rightarrow \mathrm{A}$ & $\mathrm{Gly} \rightarrow \mathrm{Gly}$ \\
MT-ND5 & 12,705 & $\mathrm{C} \rightarrow \mathrm{T}$ & $\mathrm{Ile} \rightarrow \mathrm{Ile}$ \\
MT-CYTB & 14,766 & $\mathrm{C} \rightarrow \mathrm{T}$ & $\mathrm{Thr} \rightarrow \mathrm{Ile}$ \\
MT-CYTB & 15,326 & $\mathrm{~A} \rightarrow \mathrm{G}$ & $\mathrm{Thr} \rightarrow$ Ala \\
\hline
\end{tabular}

ATP6, ATP synthase 6; CYTB, cytochrome B; COX1, cytochrome C oxidase 1; MT, mitochondrially encoded; ND, NADH dehydrogenase; RNR1, 12S RNA; RNR2, 16S RNA.
Table III. Summary of the identified mitochondrial DNA mutations in 3 esophageal cancer cell lines and 30 esophageal cancer tissues.

\begin{tabular}{lcc}
\hline Source & $\begin{array}{c}\text { Mutations in } \\
\text { protein-coding genes }\end{array}$ & $\begin{array}{c}\text { Mutations in } \\
\text { RNA genes }\end{array}$ \\
\hline Cells & 31 & 8 \\
Tissues & 182 & 34 \\
\hline
\end{tabular}

tissue samples, the C7028T mutation occurred in 26 tissue samples and the C12705T mutation was observed in 22 tissue samples (Table IV).

\section{Discussion}

mtDNA mutations occur in a variety of human malignancies, and it has been demonstrated that mutations in mtDNA are 
Table IV. Top 10 common mutations in esophageal cancer tissues.

\begin{tabular}{lccl}
\hline Locus & $\begin{array}{c}\text { Nucleotide } \\
\text { position }\end{array}$ & $\begin{array}{c}\text { Nucleotide } \\
\text { change }\end{array}$ & $\begin{array}{c}\text { Amino } \\
\text { acid change }\end{array}$ \\
\hline MT-RNR1 & 750 & $\mathrm{~A} \rightarrow \mathrm{G}$ & $\begin{array}{c}\text { Number of } \\
\text { mutated tissues }\end{array}$ \\
MT-RNR1 & 1,438 & $\mathrm{~A} \rightarrow \mathrm{G}$ & Noncoding \\
MT-RNR2 & 2,706 & $\mathrm{~A} \rightarrow \mathrm{G}$ & Noncoding \\
MT-ND2 & 4,769 & $\mathrm{~A} \rightarrow \mathrm{G}$ & Met $\rightarrow$ Met \\
MT-COX1 & 7,028 & $\mathrm{C} \rightarrow \mathrm{T}$ & Ala $\rightarrow$ Ala \\
MT-ATP6 & 8,860 & $\mathrm{~A} \rightarrow \mathrm{G}$ & Thr $\rightarrow$ Ala \\
MT-ND4 & 11,719 & $\mathrm{G} \rightarrow \mathrm{A}$ & $\mathrm{Gly} \rightarrow \mathrm{Gly}$ \\
MT-ND5 & $\mathrm{C} \rightarrow \mathrm{T}$ & $\mathrm{Ile} \rightarrow \mathrm{Ile}$ & Thr $\rightarrow \mathrm{Ile}$ \\
MT-CYTB & $\mathrm{C} \rightarrow \mathrm{T}$ & Thr $\rightarrow$ Ala \\
MT-CYTB & 12,705 & $\mathrm{~A} \rightarrow \mathrm{G}$ & 30 \\
\hline
\end{tabular}

MT, mitochondrially encoded; RNR1, 12S RNA; RNR2, 16S RNA; ATP6, ND, NADH dehydrogenase; COX1, cytochrome C oxidase 1; ATP synthase 6; CYTB, cytochrome B.

closely related to the occurrence and development of malignant tumors (11). In 1998, Polyak et al (12) reported for the first time the presence of mtDNA mutations in 7 out of 10 colon cancer cell lines. In that study, 11 of the identified mutations were single-base substitutions and 1 was an insertion; there were 12 somatic mutations and $>10$ times more mtDNA mutations than nDNA mutations. Another study detected 14 mutations through sequencing of the mitochondrial genome of 15 breast cancer tissues and distant normal tissues, of which 5 were located in the ND genes (2 mutations in ND2, 2 mutations in ND5 and 1 mutation in ND4), 2 were located in MT-COX genes, 4 were located in mtRNA, 2 were located in MT-tRNA genes and 1 was located in MT-CYTB (13). One previous study reported that the mutation frequency of mtDNA in lung cancer was approximately 100 times greater than that of normal tissue (14). Among these mutations, two, located within MT-ATP6 and MT-ND3, were significantly associated with the risk of lung cancer.

In the present study, the mtDNA coding regions of esophageal cancer cell lines and tissues were sequenced and compared with the rCRS, NC_012920.1. The sequencing results demonstrated that the majority of mutations in both the cancer cell lines and the cancer tissues were base substitutions between A and $\mathrm{G}$ or $\mathrm{C}$ and T. Recently, two large-scale studies used DNA sequencing technology to compare $>30$ tumor types, along with normal tissues collected from $>2,000$ patients, to map the mutations of the mitochondrial genome $(15,16)$. They found that many somatic cells exhibited dramatic replicative strand bias, predominantly $\mathrm{C} \rightarrow \mathrm{T}$ and $\mathrm{A} \rightarrow \mathrm{G}$ on the mitochondrial heavy strand. Similar results were observed in another study (17).

A total of 10 mutations were identified as similar between the 3 esophageal cancer cell lines, all of which were base substitution and 3 of the mutations led to amino acid replacement. A previous report identified the same three sites of amino acid changes in a study on the relationship between human life and mtDNA polymorphisms (18). Another study reported that the A8860 G transition existed in hypertrophic cardiomyopathy (HCM), and it was hypothesized that this rare polymorphism may be associated with HCM (19). The A8860G polymorphism was previously reported to reduce the rate of mitochondrial ATP production in yeasts and cultured human cells $(20,21)$. Reanalysis of the CRS was performed by resequencing the original placental mtDNA sample from Andrews et al (22). The results of this resequencing confirmed that there are rare polymorphisms in the CRS; 750A, 1438A, 4769A, 8860A and $15326 \mathrm{~A}$ all represent rare polymorphic alleles (22). Due to its widespread use, it has been recommended that in the CRS for human mtDNA, the rare polymorphic alleles should be retained so that the rCRS is a true reference sequence and not a consensus sequence (22).

In the present study, both esophageal cancer cell lines and tissues exhibited the same phenomenon, MT-ND5 and MT-CYTB had higher mutation frequencies compared with the other identified mutations. A previous study demonstrated that the MT-CYTB mutation may serve a significant role in the oxidation process in mitochondria (23).

The present results indicated that mtDNA mutations may serve a particular role in the occurrence of esophageal cancer. Mutations in mtDNA may be associated with abnormal enzyme functions in the mitochondrial respiratory chain (24). Gene mutations may alter the quality and quantity of the expression products of mitochondria, which may result in changes to the structure of the electron transport chain, leading to defects in mitochondrial function, a decline in oxidative phosphorylation function, a reduction in ATP generation and a significant increase in the number of oxygen free radicals, thereby contributing to the incidence and development of esophageal cancer. A previous study evaluated the roles of the mtDNA mutations identified in cancer cell lines using transmitochondrial cybrids to reveal that individual mtDNA mutations may be responsible for mitochondrial dysfunction (25). Our future research aims to use transmitochondrial cybrids to demonstrate individual mtDNA mutations of esophageal cancer.

\section{Acknowledgements}

This study was supported by The First Batch of Science and Technology Plan Projects of Zhengzhou in 2013 (grant 
no. 131PCXTD628), The Foundation and Advanced Technology Research Project of Henan Province (grant no. 132300410409) and the Medical Science and Technology Plan Program Grant of Henan Province (grant no. 201401009).

\section{References}

1. Larman TC, DePalma SR, Hadjipanayis AG; Cancer Genome Atlas Research Network, Protopopov A, Zhang J, Gabriel SB, Chin L, Seidman CE, Kucherlapati R and Seidman JG: Spectrum of somatic mitochondrial mutations in five cancers. Proc Natl Acad Sci USA 109: 14087-14091, 2012.

2. Eaton JS, Lin ZP, Sartorelli AC, Bonawitz ND and Shadel GS: Ataxia-telangiectasia mutated kinase regulates ribonucleotide reductase and mitochondrial homeostasis. J Clin Invest 117: 2723-2734, 2007.

3. Ishikawa K, Takenaga K, Akimoto M, Koshikawa N, Yamaguchi A, Imanishi H, Nakada K, Honma Y and Hayashi J: ROS-generating mitochondrial DNA mutations can regulate tumor cell metastasis. Science 320: 661-664, 2008.

4. Dali-Youcef N, Mataki C, Coste A, Messaddeq N, Giroud S, Blanc S, Koehl C, Champy MF, Chambon P, Fajas L, et al: Adipose tissue-specific inactivation of the retinoblastoma protein protects against diabesity because of increased energy expenditure. Proc Natl Acad Sci USA 104: 10703-10708, 2007.

5. Gasparre G, Porcelli AM, Bonora E, Pennisi LF, Toller M, Iommarini L, Ghelli A,Moretti M, Betts CM, Martinelli GN, et al: Disruptive mitochondrial DNA mutations in complex I subunits are markers of oncocytic phenotype in thyroid tumors. Proc Natl Acad Sci USA 104: 9001-9006, 2007.

6. Maynard S, Schurman SH, Harboe C, de Souza-Pinto NC and Bohr VA: Base excision repair of oxidative DNA damage and association with cancer and aging. Carcinogenesis 30: 2-10, 2009.

7. Liu SA, Jiang RS, Wang WY and Lin JC: Somatic mutations in the D-loop of mitochondrial DNA in head and neck squamous cell carcinoma. Head Neck 37: 878-883, 2015.

8. Kawasaki M, Anzawa K, Tanabe H, Mochizuki T, Ishizaki H and Nishimura K: Intra-species variation of genotypes of Exophiala jeanselmei isolated from patients in Japan. Nippon Ishinkin Gakkai Zasshi 46: 261-265, 2005.

9. Kong WJ, Wang Y, Wang Q, Han YC and Hu YJ: Comparison of three methods for isolation of nucleic acids from membranate inner ear tissue of rats. Chin Med J (Engl) 119: 986-990, 2006.

10. Zheng W, Khrapko K, Coller HA, Thilly WG and Copeland WC: Origins of human mitochondrial point mutations as DNA polymerase gamma-mediated errors. Mutat Res 599: 11-20, 2006

11. Lee HC, Chang CM and Chi CW: Somatic mutations of mitochondrial DNA in aging and cancer progression. Ageing Res Rev 9 (Suppl 1): S47-S58, 2010.

12. Polyak K, Li Y, Zhu H, Lengauer C, Willson JK, Markowitz SD, Trush MA, Kinzler KW and Vogelstein B: Somatic mutations of mitochondrial genome in human colorectal tumours. Nat Genet 20: 291-293, 1998.
13. Fendt L, Niederstätter H, Huber G, Zelger B, Dünser $M$, Seifarth C, Röck A, Schäfer G, Klocker H and Parson W: Accumulation of mutations over the entire mitochondrial genome of breast cancer cell obtained by tissue microdissection. Breast Cancer Res Treat 128: 327-336, 2011.

14. Choi SJ, Kim SH, Kang HY, Lee J, Bhak JH, Sohn I, Jung SH, Choi YS, Kim HK, Han J, et al: Mutational hotspots in the mitochondrial genome of lung cancer. Biochem Biophys Res Commun 407: 23-27, 2011.

15. Ju YS, Alexandrov LB, Gerstung M, Martincorena I, Nik-Zainal S, Ramakrishna M, Davies HR, Papaemmanuil E, Gundem G, Shlien A, et al: Origins and functional consequences of somatic mitochondrial DNA mutations in human cancer. Elife: 3, 2014.

16. Stewart JB, Alaei-Mahabadi B, Sabarinathan R, Samuelsson T, Gorodkin J, Gustafsson CM and Larsson E: Simultaneous DNA and RNA Mapping of Somatic Mitochondrial Mutations across Diverse Human Cancers. PLoS Genet 11: e1005333, 2015.

17. Yu Y, Lv F, Lin H, Qian G, Jiang YS, Pang LX, Wang YP, Wang XF, Kang YM, Li CB, et al: Mitochondrial ND3 G10398A mutation: A biomarker for breast cancer. Genet Mol Res 14: 17426-17431, 2015.

18. Yang X, Wang X, Yao H, Deng J, Jiang Q, Guo Y, Lan G, Liao DJ and Jiang $\mathrm{H}$ : Mitochondrial DNA polymorphisms are associated with the longevity in the Guangxi Bama population of China. Mol Biol Rep 39: 9123-9131, 2012

19. Houshmand M, Montazeri M, Kuchekian N, Noohi F, Nozar G and Zamani A: Is 8860 variation a rare polymorphism or associated as a secondary effect in HCM disease? Arch Med Sci 7: 242-246, 2011

20. Kucharczyk R, Salin B and di Rago JP: Introducing the human Leigh syndrome mutation T9176G into Saccharomyces cerevisiae mitochondrial DNA leads to severe defects in the incorporation of Atp6p into the ATP synthase and in the mitochondrial morphology. Hum Mol Genet 18: 2889-2898, 2009.

21. Carrozzo R, Tessa A, Vázquez-Memije ME, Piemonte F, Patrono C, Malandrini A, Dionisi-Vici C, Vilarinho L, Villanova M, Schägger H, et al: The T9176G mtDNA mutation severely affects ATP production and results in Leigh syndrome. Neurology 56: 687-690, 2001

22. Andrews RM, Kubacka I, Chinnery PF, Lightowlers RN, Turnbull DM and Howell N: Reanalysis and revision of the Cambridge reference sequence for human mitochondrial DNA. Nat Genet 23: 147, 1999.

23. Diroma MA, Calabrese C, Simone D, Santorsola M, Calabrese FM, Gasparre G and Attimonelli M: Extraction and annotation of human mitochondrial genomes from 1000 Genomes Whole Exome Sequencing data. BMC Genomics 15 (Suppl 3): S2, 2014.

24. Putignani L, Raffa S, Pescosolido R, Rizza T, Del Chierico F, Leone L, Aimati L, Signore F, Carrozzo R, Callea F, et al: Preliminary evidences on mitochondrial injury and impaired oxidative metabolism in breast cancer. Mitochondrion 12: 363-369, 2012

25. Kulawiec M, Owens KM and Singh KK: Cancer cell mitochondria confer apoptosis resistance and promote metastasis. Cancer Biol Ther 8: 1378-1385, 2009. 